\title{
Migraciones IN TERNACIONALES
}

MIGRACIONES INTERNACIONALES, VOL. 10, ART. 14, 2019

e-ISSN 2594-0279 http://dx.doi.org/10.33679/rmi.v1i1.2181

\author{
Desplazamientos discursivos y transformaciones institucionales en las prácticas de \\ solidaridad hacia migrantes centroamericanos en México
}

Discursive Displacements and Institutional Transformations in the Practices of Solidarity for Central American Migrants in Mexico

Rodrigo Parrini Roses ${ }^{1}$ y Luisa Alquisiras Terrones ${ }^{2}$

\section{RESUMEN}

En este artículo se reconstruye el caso de la señora Concepción, habitante de una localidad rural del estado de Querétaro, que fue detenida en el año 2005 por dar comida y alojamiento a migrantes centroamericanos en tránsito, y liberada dos años después. Su caso condensa una serie de modificaciones en las prácticas solidarias hacia los migrantes y permite explorar algunos desplazamientos en los discursos sociales sobre la migración y la solidaridad ocurridos en México durante los últimos quince años. Su microhistoria muestra los embates del Estado en su persecución de los migrantes centroamericanos y una ruptura en las gramáticas sociales que sostienen las prácticas solidarias. La solidaridad que practicó esta mujer rural se fundamentaba en una serie de identificaciones con los migrantes como individuos pobres y necesitados, pero también en una moral del don que enfatizaba el valor de dar desinteresadamente.

Palabas clave: 1. migración centroamericana, 2. solidaridad, 3. derechos humanos, 4. discurso, 5. México.

\section{ABSTRACT}

This article reconstructs the case of Mrs. Concepción, a resident of a rural town in the state of Querétaro, who was arrested in 2005 for providing food and shelter to Central American immigrants in transit. Two years later, she was released. Her case summarizes in a series of modifications in solidarity practices towards immigrants and allows to explore some displacements in the social discourses on immigration and solidarity that have occurred in Mexico during the last fifteen years. This story shows the attacks of the government that oppress the Central American immigrants and break the social grammars that sustain solidarity practices. The solidarity practiced by this rural woman was based on a series of empathies with the immigrants as poor and deprived individuals, but also in a moral of the gift that emphasized the value of giving selflessly.

Keywords: 1. Central American immigration, 2. solidarity, 3. human rights, 4. discourse, 5. Mexico.

Fecha de recepción: 26 de agosto de 2016

Fecha de aceptación: 6 de octubre de 2017

\footnotetext{
1 Universidad Autónoma Metropolitana-Unidad Xochimilco, rodparrini@gmail.com, https://orcid.org/0000-0002-6387-9660

2 Benemérita Universidad Autónoma de Puebla, luisa alte@hotmail.com, https://orcid.org/00000001-6723-5988
} 


\section{INTRODUCCIÓN}

Diversas investigaciones dan cuenta de la formación de una extensa y compleja red de solidaridad hacia los migrantes centroamericanos en tránsito por México (Ambriz, 2016; Olayo, 2014; Olayo, Haymes y Vidal, 2014; Solano, 2017; Squire, 2015). Desplegada por todo el país, desde la frontera sur hasta los límites con los Estados Unidos, esta red incluye organizaciones de diverso tipo, laicas y religiosas, que brindan múltiples servicios a los migrantes, desde alojamiento y comida, hasta asesoría legal y atención médica; aunque no necesariamente están conectadas entre sí, representan un recurso central para el viaje de esos migrantes por México. Si bien la historicidad de esta red solidaria ha sido escasamente investigada, los datos disponibles muestran que se constituyó, fundamentalmente, durante los primeros años de este siglo y tuvo un crecimiento sistemático a partir del año 2006.

La conformación de esta red no es sólo un fenómeno organizacional, también es uno de carácter discursivo. Si bien en ella predominan dos discursos, uno asistencial y otro de derechos humanos (Solano, 2017, p. 131), ambos pueden ser leídos como expresiones de un discurso humanitario, en el sentido que le otorga Didier Fassin (2016) a ese término, que incluye el despliegue de sentimientos morales en los asuntos políticos, la referencia a una condición compartida por los seres humanos, a pesar de sus diferencias, y "un movimiento afectivo hacia los otros semejantes" (Fassin, 2016, p. 10). El discurso humanitario, surgido en Europa y los Estados Unidos durante los últimos decenios, ayuda a la formación de lo que el autor denomina un "gobierno humanitario", que administra las existencias vulnerables en sus diversas manifestaciones y sostiene "una política de las vidas precarias" (Fassin, 2016, p. 14). La red de solidaridad que nos interesa está formada por organizaciones religiosas y no gubernamentales que despliegan una labor paralela a la del Estado que, en este caso, concentra las actividades policiales y de seguridad. La noción de gobierno humanitario propuesta por este autor excede la acción del Estado e incluye una vasta gama de actores y acciones.

Si bien el discurso humanitario y las formas institucionales constituyen hoy los modos discursivos y prácticos hegemónicos de solidaridad, a lo largo de la historia de los flujos migratorios centroamericanos, que se extiende ya por cuatro décadas, podemos encontrar otras expresiones. En este artículo identificamos un caso y un momento paradigmático en el desplazamiento histórico de las formas de solidaridad, que devela una transformación en la gestión de esos flujos en la que organizaciones humanitarias de diverso tipo adquieren un papel cada vez más relevante. La razón humanitaria no sólo corresponde a una forma de administrar las vidas precarias, apuntadas por Fassin, también sostiene un discurso moral de enorme importancia pública y mediática. En esa dirección, el caso que analizaremos representa un momento en el que las prácticas solidarias informales y tradicionales con los migrantes centroamericanos, se convierten en ejemplo moral en la defensa de sus derechos 
humanos; de este modo, el discurso humanitario convirtió a la señora Concepción, una mujer campesina que recibía a estos migrantes según antiguas pautas culturales de hospitalidad, en una activista encomiable.

El 9 de marzo de 2005 María de la Concepción Moreno, conocida como doña Conchis, fue detenida y encarcelada durante dos años y medio en el Centro de Reinserción Social de San José El Alto, Querétaro, acusada de traficar con indocumentados. En abril de 2007 una nota periodística denunciaba que "la Samaritana del Ahorcado" estaba detenida injustamente por autoridades federales, solo por dar comida y alojamiento a migrantes centroamericanos que cruzaban por su localidad. María Concepción Moreno, conocida como doña Conchis, dice la nota, "jamás imaginó en su vida que la compasión por sus semejantes la llevaría al infierno carcelario como la más temible de las delincuentes" (Escobar, 2007, p. 1). Ocho años después, otra nota sobre esta mujer, publicada en el mismo periódico, denunciaba que "la defensora de los derechos humanos", ya excarcelada, se estaba "quedando ciega" y no tenía el dinero para pagar la intervención que le prescribieron los médicos (Escobar, 2015, p. 1).

El tiempo que doña Conchis pasó en prisión deterioró su salud y sólo la ayuda de la red estatal de organizaciones dedicadas a la migración en Querétaro resolvió, parcialmente, su situación. En los años transcurridos entre ambas notas la buena samaritana se transformó en una defensora de los derechos humanos de los migrantes. Su caso se volvió paradigmático en la defensa de los ciudadanos solidarios con los migrantes en tránsito por México (Centro Proh, 2007) y colaboró con la elaboración de una Ley de Migración, que integra una perspectiva de derechos humanos en la gestión de los flujos migratorios (Arias, Carmona y Sin Fronteras, 2012; Morales, 2012; González-Murphy y Koslowski, 2011).

Ese desplazamiento que ocurre en el caso de esta mujer, desde una identidad religiosa a una política, condensa una serie de modificaciones en este campo. Doña Conchis se sitúa en el ámbito de las formas tradicionales e informales de solidaridad y hospitalidad con los extraños, afuerinos y extranjeros que cruzan numerosas localidades durante sus viajes. Sus motivaciones son fundamentalmente morales, sustentadas en el catolicismo popular. En el momento de las entrevistas, la señora Concepción no había articulado un discurso político en torno a sus acciones, ni siquiera alrededor de su detención arbitraria y los años que pasó en prisión; tampoco pensaba sus prácticas solidarias como una forma de defensa o promoción de los derechos humanos. Como dijimos, su lectura era religiosa, anclada en las significaciones y las prácticas locales ligados a la hospitalidad. Ella siempre fue una samaritana, nunca una activista.

En este texto nos centraremos en ese movimiento, aún en curso, en el campo de las prácticas hospitalarias, contrastando las narraciones de doña Conchis con los discursos de las organizaciones y los profesionales que la han ayudado. Si bien la suya es la microhistoria de una mujer que sufre los embates del Estado en su persecución de los 
migrantes centroamericanos; también muestra una ruptura de las gramáticas sociales que sostienen las prácticas de solidaridad. La historia de doña Conchis se transforma en un caso judicial, un ejemplo humanitario, un reclamo social y un motivo de asistencia, pero se deslinda de las configuraciones culturales y subjetivas de esa mujer. Es necesario considerar que la solidaridad con los migrantes no ha sido una preocupación de los gobiernos y que las redes de atención que hoy existen son relativamente recientes. Desde una perspectiva histórica, la solidaridad que doña Conchis practicaba es anterior a la de muchas organizaciones civiles y religiosas.

\section{UN TRAYECTO DE MILES DE KILÓMETROS: UNA ETNOGRAFÍA MULTISITUADA}

En este artículo interrogamos algunas relaciones microsociales de solidaridad con migrantes centroamericanos y los procesos estructurales que han transformado los flujos migratorios que transitan por México durante los últimos años. Tratamos de dilucidar los intrincados vínculos entre ambos planos desde la perspectiva de una antropología de las circulaciones (Appadurai, 2015), que permita explorar la densa trama de circulaciones constituida por sujetos, discursos, prácticas sociales, formas de gobierno, modos de organización, entre otros, que se desplazan en direcciones diversas y son interpretadas, asumidas y transformadas de múltiples maneras en distintos espacios.

El tránsito de migrantes por el país abarca miles de kilómetros, cientos de ciudades y pueblos y decenas de estados. La magnitud de este desplazamiento hace difícil su investigación, por lo que nos centramos en algunos lugares clave a través de una etnografía multilocal. ${ }^{3}$ Esta modalidad de investigación etnográfica, sostiene Marcus, "sale de los lugares y las situaciones locales de la investigación etnográfica convencional al examinar la circulación de significados, objetos e identidades culturales en un tiempo-espacio difuso" (Marcus, 1995, p. 111). Atendimos a dicha circulación en los distintos espacios que investigamos, intentando trazar las diferencias y similitudes que abonaran una reflexión específica a la vez que global sobre las formas de solidaridad con migrantes.

El caso analizado se reconstruyó a partir de diversos registros etnográficos y discursivos: observación participante, artículos periodísticos, documentos legales e institucionales y entrevistas a actores clave. Utilizando los principios metodológicos y analíticos de la descripción densa, articulamos los diferentes discursos sociales para lograr

\footnotetext{
${ }^{3}$ Realizamos trabajo de campo en localidades y ciudades de ocho estados del país. Se efectuaron entrevistas semiestructuradas y observaciones participantes en las comunidades y lugares donde fueron identificadas prácticas solidarias, en albergues y casas de migrantes y durante las labores de organizaciones civiles vinculadas al tema migratorio. En total, se realizaron 121 entrevistas: 58 a migrantes, diez a habitantes de localidades, diez a actores clave, como funcionarios y activistas, y 38 a voluntarios de las organizaciones.
} 
una interpretación intensiva acorde a la complejidad de los hechos sociales (Geertz, 2005 [1973], p. 32). A través de esta descripción de fenómenos microsociales de contextura densa se establecerán relaciones entre hechos sociales específicos y procesos sociales más amplios.

El trabajo de campo se realizó en el estado de Querétaro en el año 2015, mismo que acompañó el inicio y constitución de la Red para las Migraciones en Querétaro (RMQ). Se efectuaron cuatro visitas en los meses de abril, mayo, junio y julio de ese año, y se realizaron 14 entrevistas en la ciudad y en las localidades de: La Valla, El Ahorcado y Tequisquiapan. Dado que doña Conchis era uno de los informantes más importantes, la entrevistamos en repetidas ocasiones para conocer sus experiencias en el campo de indagación, así como las motivaciones y los valores que orientaron sus acciones. Se entrevistó a vecinos y familiares para conocer las opiniones y percepciones que se producen en torno a las acciones solidarias de esta mujer. Finalmente, se entrevistó a miembros de organizaciones y de la sociedad civil que se solidarizaron con doña Conchis, después de su liberación.

\section{HABITAR INTERSTICIOS: FLUJOS MIGRATORIOS CENTROAMERICANOS Y FORMAS DE SOLIDARIDAD}

Desde los años ochenta del siglo pasado han cruzado por México masivos flujos de migrantes centroamericanos que se dirigen a los Estados Unidos (ITAM, 2014; Servicio Jesuita a Migrantes, 2013). Los números no son precisos, pero sus aproximaciones develan un movimiento de miles de personas que toman diferentes rutas (Casillas, 2008). Desde inicios de este siglo, ese movimiento de personas se ha transformado en un asunto político relevante y hoy en día es un tema prioritario en las relaciones entre los países involucrados: Estados Unidos, México y los países del Triángulo Norte de Centroamérica, Guatemala, El Salvador y Honduras.

A lo largo de los últimos quince años podemos identificar dos inflexiones importantes en ese campo: la primera ocurrió luego de los atentados contra ciudades estadounidenses en el año 2001 y transformó la seguridad fronteriza en un tema de seguridad nacional para el gobierno de los Estados Unidos (Alden, 2012; Artola, 2005; Calleros, 2010; Castillo, 2005); la segunda, a mediados de 2014, cuando el incremento del flujo de menores centroamericanos no acompañados que eran detenidos en el país del norte justificó una serie de medidas de contención en la frontera sur de México, a través del Programa de Frontera Sur (Castañeda, 2015; Villafuerte y García, 2015). Si bien no profundizaremos en esas modificaciones, el caso de doña Conchis se configura en el periodo que ambas marcan.

En torno a la migración centroamericana que transita por México se ha creado una densa red de actores e instituciones de diverso tipo y con objetivos distintos $\mathrm{y}$, muchas 
veces, contrapuestos. No hay estudios en México que den cuenta de la complejidad de esa trama. A lo largo de la investigación que nos concierne, pudimos distinguir cinco planos de configuración de los procesos migratorios centroamericanos:

1. Los migrantes, que son un colectivo enormemente complejo, aunque presente algunas características comunes (Servicio Jesuita a Migrantes, 2013);

2. Las comunidades y localidades por donde este flujo transita, que incluyen desde villorrios de pocos habitantes hasta colonias de megalópolis (Flores, 2011; Fuentes y Ortiz, 2012);

3. El Estado, que despliega políticas heterogéneas en este campo y que van desde la detención y deportación hasta la protección de los derechos humanos;

4. La red de organizaciones de diverso tipo que resguarda a los migrantes: albergues, comedores, casas; o que trabajan en torno a este fenómeno: universidades, centros de investigación, organizaciones no gubernamentales, medios de comunicación.

5. Varios tipos de delincuencia que medra de los migrantes (Amnistía Internacional, 2011; CNDH, 2011).

Esa red tiene expresiones locales y nacionales, incluso transnacionales, y se extiende en casi todo el país, con diferencias de densidad. ${ }^{4}$ No son planos paralelos, sino una red intrincada, variable y muy compleja, en la que también se pueden identificar nodos en los que se interceptan unos con otros.

En el caso que estudiamos, las prácticas de solidaridad ocurren en tres de esos planos: entre los mismos migrantes, entre habitantes de las localidades por las que transitan los migrantes, entre ellos y las redes de organizaciones civiles y eclesiásticas que los asisten de diversas maneras durante su viaje. El Estado es un actor omnipresente en la regulación y control de esos colectivos, pero no despliega prácticas de solidaridad; sus acciones están normadas legalmente y sus prácticas institucionales operan dentro de una lógica de políticas públicas. Los actores criminales tampoco realizarían prácticas de solidaridad o, al menos, no son su objetivo.

Por eso, la red de sobrevivencia y atención que colabora en el desplazamiento de los migrantes se trenza, por así decirlo, con las prácticas estatales que "aseguran" a los migrantes y los "devuelven", y con las criminales que los asaltan, extorsionan y/o secuestran. En una localidad, una zona donde los migrantes reciben ayuda puede convivir con otra en la que son extorsionados; los albergues cohabitan con sitios de tráfico de personas; en un lugar donde los migrantes se alojan también pueden ser detenidos. Esta superposición de los actores que habitan o utilizan un espacio social determinado y las

\footnotetext{
${ }^{4}$ En estados como Chiapas existe una alta densidad estatal y de sociedad civil; en otros, como Tamaulipas, predomina el Estado y el crimen organizado.
} 
prácticas que ahí se realizan impide generar descripciones o análisis unívocos. Si bien esa ambivalencia no compromete a los actores involucrados y no implica que unos y otros estén vinculados, delinea una cartografía de la solidaridad y la violencia muy compleja, en la que se entrecruzan actores diversos, múltiples motivos y prácticas heterogéneas.

Esto no repercute sólo en los migrantes y su viaje, también en los otros actores que distinguimos, especialmente en las personas o grupos que realizan prácticas cotidianas de solidaridad fuera de los contextos organizacionales (redes, albergues, casas de acogida, comedores). El peligro, en ese sentido, se podría expandir hacia todos aquellos que participan de este flujo incesante de personas. En algunas localidades, hemos registrado casos de personas que han sido amenazadas por redes delictivas, albergues que fueron quemados por delincuentes, vecinos que se atemorizaron cuando percibieron que actos tan sencillos como dar un vaso de agua o algo de comida podrían traerles problemas.

Pero el riesgo no proviene sólo de actores delictivos, también podría proceder de instancias estatales. Ese fue el caso de doña Conchis, que fue detenida por agentes federales, acusada de tráfico de personas.

Desde la perspectiva de las prácticas de solidaridad, ambas experiencias de riesgo muestran que las gramáticas de la vida cotidiana, asentadas en prácticas de hospitalidad y generosidad, pero también en estrategias de reconocimiento y vinculación con los extraños, se ven alteradas por estas intervenciones estatales o criminales. ${ }^{5}$ Para la señora Concepción fue una sorpresa que la detuvieran por dar de comer a las personas que se lo pedían o por brindarles cobijo; en sus esquemas de significación, esas prácticas no constituían un delito. Esto redundó en que la intervención de las instituciones de impartición de justicia resultara incomprensible para ella y su comunidad.

En la definición de esos sentidos, los actores involucrados no tienen el mismo poder y sólo dos de ellos pueden contraponerse discursiva y prácticamente: el Estado y las redes de organizaciones de solidaridad y derechos humanos. Los habitantes de las localidades que ofrecen ayuda a los migrantes, los pequeños grupos, o las familias que los acogen, pueden elaborar significados para sus prácticas, pero no pueden participar del debate nacional o internacional que genera la migración.

\footnotetext{
${ }^{5}$ Sin embargo, no consideramos que una amenaza se compare con la otra: doña Conchis fue acusada por autoridades judiciales, tuvo un juicio y fue defendida por abogados $y$, finalmente, quedó en libertad. Su caso expuso las arbitrariedades del aparato judicial y las contradicciones estatales en relación con la migración que transita por México, pero sucedió en marcos institucionales reconocibles.
} 


\section{PEDIR PARA DAR: FORMAS TRADICIONALES DE SOLIDARIDAD}

El don ha sido un concepto fundamental en el pensamiento antropológico, especialmente desde la publicación del clásico ensayo de Marcel Mauss dedicado a esa práctica cultural (Mauss, 2012 [1925]). Como ha tenido un desarrollo tan extenso, su conceptualización está llena de matices (Abduca, 2007; Descola, 2012; Godelier, 1998; Testart, 2013). Para nuestra argumentación, deseamos recuperar una distinción, elaborada por algunos investigadores, entre don e intercambio (Descola, 2012 y Testart, 2013). A diferencia del intercambio, escribe Philippe Descola, "el don es, ante todo, un gesto de sentido único que consiste en dejar algo a alguien sin prever otra compensación que el eventual reconocimiento del destinatario, puesto que la devolución del beneficio nunca está garantizada en el don" (Descola, 2012, p. 451).

Las prácticas de solidaridad de la señora Concepción se inscriben en ese registro. Ella relata que empezó a darles de comer a algunos migrantes que pasaban por su casa y le pedían alimento. ${ }^{6}$ Las vías del tren dibujan uno de los bordes de su comunidad; están a menos de un kilómetro de las casas más próximas y marcan una línea imaginaria para dar paso a los sembradíos. La proximidad a las vías del tren es la razón por la cual, desde hace décadas, los pobladores tienen una relación estrecha con los migrantes centroamericanos, en su mayoría provenientes de Honduras.

Tal como lo pudimos atestiguar durante el desarrollo de las entrevistas, ella les daba lo que tenía para consumo propio o de su familia, no preparaba una comida especial para los migrantes, ni contaba con un comedor que sirviera para atenderlos. Ellos aguardaban, fuera o dentro de su casa, el alimento que les era servido. Fundamentalmente, los integraba a sus propias pautas de alimentación cotidiana. El don, en su caso, era una ampliación de los comensales y de los alimentos con los que se cuenta.

Empecé con unos que pasaron y: "me regala un taquito y me regala un vasito de agua", y empecé a darles un taquito de... pues de frijoles o de que uno llegase... lo que uno pueda y les di taco de frijolitos o sopita, su cafecito. Cuando tengo, les doy su café, los paso y "siéntense", es como empecé a darles un taquito a ellos (doña Conchis, Querétaro, comunicación personal, julio de 2015).

El número de comensales se incrementó a lo largo de los años y la informante relata que a veces llegó a alojar a más de cien migrantes en su casa. Cuando no alcanzaba la comida, les pedía a sus vecinos para poder ofrecerles algo a los viajeros. Doña Conchis justificaba su ayuda en una similitud radical con respecto a esas personas: "son seres humanos como

\footnotetext{
${ }^{6}$ La informante vive en la comunidad de Epigmenio González, conocida popularmente como El Ahorcado, en el municipio Pedro Escobedo, Querétaro. Tiene aproximadamente 2828 habitantes, cuenta con un centro de salud, una escuela primaria y secundaria y una parroquia. La principal actividad económica de la zona es la agricultura y la ganadería.
} 
nosotros". Esa igualdad identificatoria, le permitía entender sus razones y aceptarlos dentro de su vida cotidiana: "no porque vienen de otro lado, los discrimina, hablan de ellos, que esto y el otro, pero la realidad nadie la sabe, por qué se salen de sus casas, nadie."

La identificación, escribe Philippe Descola, es "el esquema más general por medio del cual establezco diferencias y semejanzas entre unos existentes y yo mismo, al inferir analogías y contrastes entre la apariencia, el comportamiento y las propiedades que me adjudico y los que les atribuyo" (Descola, 2012, p. 177). En ese sentido, el esquema de una humanidad compartida será el asiento de las prácticas de solidaridad que realizaba esta mujer; también es el límite de las diferencias, porque aunque los migrantes sean extraños y extranjeros, es posible entender, mediante esquemas identificatorios, sus motivaciones y sus experiencias. Sin embargo, esa identificación no sostiene un discurso humanitario como el descrito por Fassin (2016), entre otros. A la señora Concepción los vínculos establecidos con los migrantes le permitieron conocer con mayor profundidad sus motivaciones y sus contextos: "a mí me platican que esto y que el otro; que luego también allá no hay trabajo, no hay dinero, y sus hijos van creciendo y tienen que tener para darles un taco".

La motivación de doña Conchis era fundamentalmente, afectiva: a ella le gustaba ayudarlos "de corazón" y "darles lo poco que tiene". El don no se sustenta en un exceso que debe circular" sino en una escasez sistemática. No se da lo que sobra, se da lo que falta; pero, a su vez, se dona a quien no puede devolver. Si bien el intercambio no tiene que ser simétrico, en este contexto, por la pobreza de los migrantes y lo transitorio de su estadía, cualquier devolución es imposible. Aunque la informante no lo dice explícitamente, creemos que aquí también funciona un esquema identificatorio, que se integra al de la humanidad compartida. Doña Conchis y los migrantes son igualmente pobres, aunque en situaciones distintas. La escasez no es sólo una disponibilidad de bienes, también es una forma de leer el mundo y las propias vidas. Humanos y pobres: eso comparten la donadora y los donatarios.

Cuando la escasez era muy intensa, la señora Concepción se convertía en peticionaria de ayuda. Ella lo condensa de manera magistral: pide para dar. En ese sentido, relata:

Cuando se quieren bañar, a veces no tengo ni jabón. A veces ahí ando pidiendo a mis nueras, y ya me dan y: "ya báñense, muchachos". De ropa, igual, luego no tengo aquí nada de ropa ni zapatos, corro a pedir: "oiga, regáleme un pantaloncito, una camisita para un muchacho, regáleme esto para este otro muchacho, no trae zapatitos, ya trae su pantalón bien mugroso, bien sucio", "ándele, María". Te digo, más me da esta señora, que es la que más me da,

${ }^{7}$ Como en el caso de la limosna expuesto por Mauss: "fruto de una noción moral del don y de la fortuna, por un lado, y de una noción de sacrificio, por el otro" (Mauss, 2012 [1925], p. 103). 
cuando estaban todos sus hijos, ¿verdad? porque ahora ya no están. Pero así le hago, pido para dar (doña Conchis, Querétaro, comunicación personal, julio de 2015).

Ahora bien, parece que en cualquier práctica de don siempre ronda el fantasma del intercambio, es decir, del interés que se contrapone con la gratuidad. La señora Concepción ubica sus motivaciones y sus prácticas en el campo de la gratuidad: "nunca les cobré, yo nunca les dije: 'ahora páguenme el hospedaje, ahora les voy a cobrar renta o denme pa' jabón, denme', nunca les cobré." Dadas las tensiones y fuerzas que concita, aunque no necesariamente resuelva, Godelier describe el don como "una práctica ambivalente" (Godelier, 1998, p. 23). La obligación de devolver es una de esas tensiones: para Mauss ella estaría en "la naturaleza del don" (2012 [1925], p. 145); en cambio, para Descola (2012) y Testart (2013) un don no exige ofrecer un contradón, "en el sentido de que el favor inicial implique una prescripción apremiante" (Descola, 2012, p. 452).

¿Se puede dar sin pedir nada a cambio?, ¿existe un don que no exija un contradón?, ¿puede ser gratuita la solidaridad a largo plazo y sistemática hacia ciertos colectivos? La ambivalencia y las sospechas que rodean las motivaciones de doña Conchis la ubican en un nodo conflictivo de las relaciones sociales contemporáneas; los rumores y los chismes locales la acusaban de medrar con los migrantes. Como dijimos, en la gratuidad y el interés se concentran tensiones culturales significativas para pensar los vínculos sociales, ya no sólo en su descripción formal, también en su comprensión hermenéutica. Marcel Mauss desecha, a través de los múltiples ejemplos que expone en su Ensayo, la posibilidad de una gratuidad desinteresada y destaca que detrás del carácter voluntario de esas prestaciones, "en apariencia libre y gratuito", "sólo hay ficción, formalismo y mentira social" y, finalmente, "obligación e interés económico" (Mauss, 2012 [1925], pp. 253-254). Doña Conchis relata que:

Hay unos que me preguntan que si les vendía yo la comida o la ropa, yo se los doy así, de todo corazón, de buena voluntad y de corazón. Yo todo lo que les doy, se los doy de corazón porque, no sé, porque siempre nos ha enseñado mi mamá de que si damos nos rinden más las cosas, pero si está una de codas o de agarradas, no les rinden sus cosas. Yo por eso les doy a ellos, tenga o no tenga, nomás que ande consiguiendo para darles, les doy, y esa es mi idea, y seguir apoyándolos y ayudándolos (doña Conchis, Querétaro, comunicación personal, julio de 2015).

Es como si culturalmente el don respondiera, al menos en el campo que investigamos, a las dos propuestas analíticas que ya esbozamos: sólo es interés disfrazado o es gratuidad sin retorno. Algunas voces de la localidad sospechan de la generosidad de la señora Concepción, como Mauss duda de la que disfraza al interés económico. El antropólogo 
menciona tres palabras relevantes: ficción, mentira y formalismo. La pregunta es cómo distinguir, en este campo, lo no ficcional, lo verdadero y lo sustantivo, de lo que no lo es.

Tal vez una pista para resolver este intríngulis sea preguntar quién podría o debería regresar aquello que se dona. En este sentido, Descola destaca que "la obligación de reciprocidad con respecto al benefactor es [...] puramente moral" (Descola, 2012, p. 452). Si no se cumple con ella, el problema es ético antes que contractual. Pero también se puede pensar una práctica del don en la que el donador vea restituida su generosidad mediante la intervención de un tercero, distinto del donatario. La señora Concepción reconoce esa lógica de otorgamiento/devolución; dice "yo tengo esa idea de que si los ayudo, Dios me ayuda; si no, Diosito no va a poner las manos en alguien que me dé algo de despensa o algo" (doña Conchis, Querétaro, comunicación personal, julio de 2015). ¿Quién devuelve lo que se ha dado? Dios, responde ella. ${ }^{8}$ Esta mujer percibe que Dios la ayudó cuando estuvo detenida y que el abogado que se hizo cargo de su caso y que logró liberarla, era "un ángel enviado por Dios".

Pero, por otra parte, ella también esboza otro principio de circulación de los bienes y de la riqueza, que es moral antes que técnico: "si damos, nos rinden más las cosas, pero si está una de codas o de agarradas, no les rinden sus cosas". Es decir, en la interpretación de sus prácticas esta informante triangula la relación donador/donatario, añadiendo a este tercero sobrenatural que devuelve de otro modo y desde otro plano aquello que se dona en este mundo. También devela un principio de circulación que sostiene que si las cosas no se dan se estancan y no rinden; la abundancia provendría de la apertura a dar lo que se tiene, aunque sea poco. Dar es lo contrario de agarrar. Esta es una enseñanza materna, que se trasmite entre mujeres que no han tenido trabajos asalariados, pero que han mantenido a sus familias.

Es interesante, para regresar a un argumento que delineamos antes, que en ambos casos sea imposible distinguir ficción de realidad, o verdad de mentira. Son redes de significación, en las que las prácticas se realizan y adquieren sentido, las que están en juego. No hay otro fondo que no sea la misma cultura, con sus ambivalencias y ambigüedades. Nos encontramos ante "[...] una multiplicidad de estructuras conceptuales complejas, muchas de las cuales están superpuestas o enlazadas entre sí, estructuras que son al mismo tiempo extrañas, irregulares, no explícitas" (Geertz, 2005 [1973], p. 24).

Quedamos así ante una densa red de interpretaciones que enturbia cualquier comprensión unívoca de las prácticas de solidaridad. Hemos identificados dos límites: la gratuidad y la ganancia. No sólo en el caso de la señora Concepción, también en otros

8 La entrevistadora le llevó una despensa a la señora Concepción cuando fue a entrevistarla, ella lo lee desde esa perspectiva: "como ahorita tú, gracias a Dios, fue por Dios y por ti que traes eso." 
casos que hemos investigado en diversos puntos del país, en los que la posibilidad de que la solidaridad sea un negocio socava la base moral que requiere para legitimarse.

Si regresamos a Godelier (1998) y la doble relación que produciría el don, creemos que la solidaridad se transforma en un estatus relativo en el caso de doña Conchis. Cuando ella enfrenta el juicio no lo hace con argumentos legales, sino ante todo morales.

Me habían sentenciado a seis, seis años. Ahora le decía al juez: "denme los que quiera, al cabo que primeramente se queda con su mitad de sentencia", "que es muy agresiva, es muy grosera", "porque usted está faltando a la ley, yo no hago nada malo. Sí, lo reconozco, y se lo digo en su cara, juez, yo que no tengo y que soy pobre, me gusta darles un taco, dejarlos que se duerman, no se los niego, pero que yo conozca coyotes, para dárselos, no; y usted que pueda tener la comodidad económicamente, no les da, es un codo, un agarrado", "ique le voy a subir la sentencia!", "súbamela a diez, quince años, yo sé que se va a quedar con su sentencia, yo tengo fe que yo voy a salir", "no, pero que nos está faltando al respeto", "me la está faltando más usted, porque yo no debo nada; sí les doy de comer, les doy un taquito, ahora, vaya y saque fotografías de mi casa cómo la tengo, que soy muy pobre" (Doña Conchis, Querétaro, comunicación personal, julio de 2015).

Este relato, de una Antígona rural y campesina que se enfrenta al juez reclamando la validez moral de sus conductas, se sostiene en el prestigio ético que adquiere quien dona sin pedir devolución. Si en esta relación se hubiese contraído una deuda no sólo concierne al donador y al donatario, también involucra una sociedad completa que debe reconocer los méritos de las prácticas solidarias. En este caso, no estamos ante regulaciones explícitas, es un sentido común el que obliga a alentar a quien dona desinteresadamente. Ante un orden social en el que priman las relaciones de intercambio y el interés, la gratuidad y la generosidad son talismanes que resguardan una serie de prácticas culturales y conforman especies de santuarios éticos, amenazados por las formas imperantes de vinculación entre sujetos y colectivos.

La señora Concepción le espeta al juez su propia pobreza y generosidad como si, en un movimiento antitético, se intensificara la moralidad de su comportamiento. No tiene nada, pero de todos modos da. Ella le dice al funcionario que "no debe nada". Sus prácticas solidarias no han producido una deuda; es decir, ella luego de dar no debe devolver. Es como si el don empezara y terminara en sus prácticas. Dado que discute con un juez, de algún modo le dice al Estado que está libre de deudas, pero también de delito. Nos interesa destacar que en esas palabras la informante reivindica un tipo de relaciones sociales distinto al que compete a la ley y a las instituciones estatales. La antigüedad del don como fundamento de las relaciones sociales le da la razón. Pero esta mujer carece de argumentos que le permitan defender sus prácticas ante otras relaciones y otros discursos. 


\section{¿SAMARITANA O ACTIVISTA?}

Cuando el Centro de Derechos Humanos Miguel Agustín Pro Juárez (Centro Prodh) conoció el caso, los recursos ordinarios se habían agotado. Al asumir la defensa integral de doña Conchis interpusieron un amparo directo contra la resolución que confirmó la sentencia dictada por el juez. Paralelamente, iniciaron una campaña pública para exigir su liberación. E1 23 de agosto de 2007 el Primer Tribunal Colegiado de Circuito del Estado de Querétaro concedió la razón a la defensa; considerando que las pruebas de cargo en contra de doña Conchis presentaban vicios de forma y fondo que les restaban validez, otorgó la protección de la justicia federal y ordenó la emisión de una nueva sentencia. Tras esta resolución, el Tribunal dictó nueva sentencia en la que determinó absolver en apelación a Concepción y ordenar su inmediata liberación.

De acuerdo a esta organización de derechos humanos, el caso de Concepción Moreno es emblemático para ejemplificar la discrecionalidad de las políticas públicas relacionadas con los migrantes centroamericanos en México. Además, hizo evidente dos temas fundamentales en la agenda de derechos humanos en el país: la necesidad de consolidar la reforma del sistema de justicia penal y la vulnerabilidad de los defensores de los derechos humanos (Centro Prodh, 2008).

Como un logro posterior, el 5 de marzo de 2008 la Suprema Corte de Justicia de la Nación resolvió que sólo incurrirán en un delito quienes alberguen o transporten personas indocumentadas para obtener un fin económico. Dicha decisión exonera del ilícito a quienes lo hacen por razones humanitarias o sin fines de lucro, "y que siguiendo la tradición mexicana de asistencia, apoyo y ayuda al necesitado, desvalido o que se encuentre en una situación de desventaja, alberguen o transporten a extranjeros indocumentados, lo que supone, en todo caso, la buena fe" (SCJN, 2008, p. 45). En este caso, se juega un deslinde estatal entre prácticas lucrativas y solidarias. Nuevamente, el dinero y el interés serán centrales para diferenciar unas de otras.

Pero una vez que la señora Concepción fue detenida y su caso defendido por una organización especializada en derechos humanos, las interpretaciones que se elaboraron fueron distintas a las que ella proponía. Su historia se desplazó y abandonó los esquemas conceptuales de su comunidad. Este proceso de inscripción de las prácticas solidarias en otros esquemas interpretativos, pero también su traducción a otra organización de las relaciones sociales, lo leeremos como un desplazamiento hacia un discurso humanitario, en palabras de Fassin (2016), de las formas de solidaridad hacia migrantes .

Las prácticas solidarias contemporáneas articulan redes complejas de actores y recursos locales, nacionales e internacionales (Solano, 2017, p. 137). Cuando Centro Prodh asumió el caso de la señora Concepción, el entramado era menos denso que el actual y durante los últimos años se han incorporado nuevas organizaciones, o han incrementado su presencia las ya existentes. Considerando que, como dijimos, no se trata de una red solidaria 
homogénea y sus prácticas son múltiples, su coherencia hay que buscarla en un registro discursivo, antes que práctico. El discurso humanitario dota de sentidos muy poderosos a la acción de estas organizaciones, dado que el vocabulario "de la compasión y de lo humanitario" forma parte de la vida política, tanto a nivel nacional como internacional (Fassin, 2016, p. 11).

Doña Conchis muestra la extensión discursiva del humanitarismo a otros ámbitos, que se mantuvieron, hasta hace poco, fuera de su influencia. La razón humanitaria triunfa cuando logra articular discursivamente a los principales actores de este campo, pero también cuando abarca el conjunto de prácticas de solidaridad, incluso aquellas que surgieron en otros esquemas culturales. La polisemia que podría rodear la solidaridad con los migrantes da paso a una hegemonía discursiva humanitaria.

Pero no sólo se trata de una transformación de las formas de significación de ciertas prácticas sociales, también de su inscripción en otro régimen institucional. Como dijimos, lo que estaba constituido, básicamente, por encuentros cara a cara, más o menos esporádicos, que se realizaban en algunos espacios cotidianos, como las casas o las calles, de los territorios por donde transitan migrantes durante su viaje, se transformó en una red de lugares específicos, dedicados a darles algún tipo de atención a esta población (comida, alojamiento, atención sanitaria o legal, entre otros). No es un asunto de lenguajes distintos, son modos de vida y formaciones discursivas diferentes que se entrecruzan.

Cuando los defensores del Centro Prodh abordan el caso de la señora Concepción, la describen como alguien que "promueve la tolerancia hacia los migrantes", que "otorga ayuda humanitaria" y como "un símbolo de una oposición pacífica contra el discurso del Estado." Ninguna de estas descripciones corresponde a las que nuestra informante elabora:

La Sra. Moreno ha buscado promover una mayor tolerancia hacia los migrantes e impulsar una actitud respetuosa hacia dicha población por parte de los miembros de su comunidad. Por otorgar ayuda humanitaria a los migrantes, la Sra. Moreno se ha convertido en un símbolo de oposición pacífica contra el discurso del Estado que criminaliza a los migrantes y les niega sus garantías fundamentales (Centro Prodh, 2007, p. 3).

Si bien la organización que defiende a la señora Concepción se confronta con las arbitrariedades de los aparatos de justicia, utiliza un lenguaje jurídico que es comprensible para dichas instituciones. Dista de ese encuentro verbal desafiante que relata esta mujer con el juez que la encarcela. Para esas tramas, la señora Conchis es una activista y defensora de derechos humanos; para ella, su lugar es el de una mujer generosa y maternal.

No todos los actores de las prácticas solidarias están ubicados en la misma posición, ni los espacios son equivalentes. La heterogeneidad de las prácticas también implica la desigualdad de las relaciones que producen o en las que se sustentan. En ese sentido, la señora Concepción se encuentra en una posición particular: hasta su hogar llegan personas 
aún más vulnerables que ella y sólo cuenta con una valía moral que no tiene repercusiones institucionales. Lejos de los lenguajes y conocimientos técnicos, esta mujer puede elaborar un relato cotidiano con sus esquemas conceptuales y morales, pero no puede enfrentar los embates de las instituciones y requiere de asistencia especializada.

Paradójicamente, en los esquemas identificatorios en juego esta señora está más próxima a los migrantes que las organizaciones que trabajan para ellos. La humanidad y la pobreza, elaborados en los lenguajes cotidianos, son anclas de sus prácticas, pero también modos de vinculación con los otros. Las formas institucionales de solidaridad implican lenguajes técnicos y saberes profesionales. Si bien lo humanitario, dice Fassin, "deviene un lenguaje que relaciona inextricablemente los valores y los afectos" (Fassin, 2016, p. 11), el lenguaje de las organizaciones es antes técnico que afectivo, internacional y no comunitario. Sin participar de ese lenguaje humanitario, articulado en torno a la compasión y la humanidad compartida, doña Conchis ofreció asilo y alimento a los migrantes que se lo pidieron. Es decir, satisfacía necesidades que hoy forman parte de la acción humanitaria sin establecer relaciones con las instituciones ni los discursos que luego se harían cargo de ellas. Como samaritana o como activista, esta mujer fue siempre un actor marginal en el mapa de la solidaridad, que no avizoraba otros lenguajes que no fueran los del don ni justificaciones distintas a las religiosas o morales. En alguna medida, frente a la compasión abstracta del discurso humanitario, ella enarboló una hospitalidad cálida, en términos de Solano (2017, p. 136), escasamente narrada. No se trata solamente de trazar una distinción entre una lógica cristiana cálida y otra estatal fría, sino entre las microprácticas que se sustentan en un encuentro azaroso con el otro y aquellas que delinean modos estables de solidaridad (asistenciales o críticos), que articulan de formas diversas los macro-discursos de la compasión humanitaria transnacional.

\section{UNA DEUDA CORPORAL: REPARAR EL DAÑO}

Cuando se publicó la segunda nota periodística que citamos en la introducción, la señora Concepción se encontraba enferma: una diabetes diagnosticada antes de su detención había avanzado y amenazaba con dejarla ciega. Durante los primeros cuatros meses de su reclusión, no pudo tomar los medicamentos que controlaban su enfermedad. Después de ser amparada y liberada, su caso fue olvidado y ella regresó a su vida habitual y a las carencias.

En el año 2015 cuando realizamos el trabajo de campo (diez años después de su detención y ocho años de su absolución y liberación) la señora estaba alarmada por su situación; en las mismas fechas el periodista que había denunciado su encarcelamiento arbitrario dio cuenta de su deterioro. La Red para las Migraciones en Querétaro decidió acoger el caso de doña Conchis. Los problemas de salud y la pobreza extrema son dos condiciones que la afectan a ella y a otros miembros de su familia y de la comunidad. 
La posición de la señora Concepción había cambiado de modo considerable. En estos momentos, ella era la que requería ayuda y ésta provenía de las redes especializadas en migración y derechos humanos. Como efecto del Programa Frontera Sur, a partir de 2014 disminuyó considerablemente el tránsito de migrantes por su localidad. Ella continúa reivindicando su generosidad, pero las prácticas de solidaridad son cada vez más escasas ${ }^{9}$.

De alguna manera, el encarcelamiento produjo un deterioro profundo en esta mujer, aunque la conectó con redes de solidaridad institucionalizadas. Ese vínculo se fue diluyendo en el tiempo, pero se reactivó en el año 2015. Entonces su interés era cómo resarcir el deterioro que experimentó; algunos plantearon que solicitara una reparación del daño. Ella comenta al respecto:

[Me dicen] "pide indemnización". Yo a esas horas no pedí nada (cuando salió de la cárcel absuelta de los cargos), porque estaba gustosa de estar con mis hijos, de salir de allá adentro, y bueno, fue una tontera mía no pedir la indemnización que dicen que me hubieran dado; ahora la quiero pelear, pero no sé si se pueda (doña Conchis, Querétaro, comunicación personal, julio de 2015).

¿Quién puede reparar el daño producido?, ¿se puede subsanar la injusticia mediante una indemnización? No tenemos respuesta clara a esas preguntas, pero creemos que los últimos episodios de esta historia muestran que la señora Concepción requiere de las redes institucionales. No es una activista, pero es una persona solidaria afectada por las políticas estatales en torno a la migración. Las prácticas del don se difuminan tras ese enmarañamiento institucional; los gestos solidarios cotidianos se transforman en huellas profundas de la acción de las instituciones. Esta señora comienza a pagar una deuda mediante su propio cuerpo, como si la pena fuera también el cálculo de un costo. La sospecha que Mauss extiende sobre la generosidad desinteresada se transforma en una evidencia corporal: el don se castiga, la generosidad se persigue y los costos se transfieren a aquel que actúa movido por otros valores o por otros esquemas culturales que no sean los del interés y el cálculo.

Nuestra informante queda atrapada de modo irremediable, a nuestro entender, entre la deuda social y cultural que paga con su cuerpo, pero que fue impuesta por el Estado, y las soluciones técnicas que le ofrecen las redes de solidaridad institucionalizadas: exigir que se repare el daño, es decir, que su sufrimiento se transforme en un monto de dinero que lo compense.

\footnotetext{
${ }^{9}$ Dado que el trabajo de campo se realizó durante los años 2015 y 2016, nuestros análisis se remiten a lo que en ese momento sucedía con los flujos migratorios y las prácticas de solidaridad. No obstante, la rapidez de las transformaciones acaecidas en los últimos tres años obliga a situar históricamente cualquier descripción que se haga de la migración centroamericana por México.
} 
¿Se puede reparar el daño a esquemas culturales y a formas de vida?, ¿puede calcularse monetariamente su valor simbólico y experiencial?, ¿es posible restituir las relaciones sociales dañadas, los vínculos rotos, los valores desmentidos? Tal vez la intervención más exitosa habría sido reivindicar la importancia social y cultural de las prácticas de don, poner en cuestión el reinado absoluto del interés, desmentir las formalidades y ficciones de generosidad con estas historias cotidianas, pero reales, en las que alguien puede dar algo sin pedir nada a cambio.

\section{REFERENCIAS}

Abduca, R. (2007). Reciprocidad y don no son la misma cosa. Cuadernos de Antropología Social (26), 107-124.

Alden, E. (2012). Immigration and Border Control. Cato Journal, 32(1), 107-124.

Ambriz, M. (2016). Migrantes hondureños en la Casa de la Caridad Hogar del migrante, "Monseñor Luis Morales Reyes" en San Luis Potosí. Un oasis en el desierto. Para obtener el grado de Maestra en Antropología Social. El Colegio de San Luis.

Amnistía Internacional. (2011). Victimas invisibles. Migrantes en movimiento en México. Amnistía Internacional. Recuperado de: http://amnistia.org.mx/nuevo/wpcontent/uploads/2014/07/Mexico_Victimas_Invisibles_28_04_2010.pdf

Appadurai, A. (2015). El futuro como hecho social. Buenos Aires: Fondo de Cultura Económica.

Arias, Carmona y Sin Fronteras. (2012). Evolución y retos del marco normativo migratorio en México: una perspectiva histórica. Recuperado el 10 de marzo de 2016, de Sin Fronteras: http://www.sinfronteras.org.mx/attachments/article/1406/informeMigracion_web.pdf

Artola, J. (2005). Debate actual sobre migración y seguridad. Migración y desarrollo (5), 136-150.

Calleros, J. (2010). El vínculo entre seguridad nacional y migración en México. Revista Mexicana de Politica Exterior (88), 9-43.

Casillas, R. (2008). Las rutas de los centroamericanos por México, un ejercicio de caracterización, actores principales y complejidades. Migración y Desarrollo (10), 157-174.

Castañeda, A. (2015). Programa Frontera Sur o la política de persecución de migrantes en México. Recuperado el 21 de febrero de 2016, de Observatorio de Legislación y Política Migratoria. Recuperado de: http://observatoriocolef.org/ admin/documentos/Plan $\% 20$ frontera $\% 20$ sur $\% 20$ Novie mbre\%20FINAL.pdf 
Castillo, M. (2005). Fronteras, migración y seguridad en México. Alteridades, 15(30), 5160 .

Centro de Derechos Humanos "Miguel Agustín Pro Juárez". (Centro Proh). (2007). El asalto a la defensa de los derechos humanos de los migrantes. Actos de intimidación $y$ castigo a defensores mexicanos y estadounidenses que denuncian abusos y proporcionan ayuda humanitaria a migrantes indocumentados. Centro Prodh. Recuperado http://centroprodh.org.mx/index.php?option $=$ com_docman\&task $=$ doc_details\&gid $=3$ 6\&Itemid $=38 \&$ lang $=$ es

Centro de Derechos Humanos "Miguel Agustín Pro Juárez". (Centro Proh). (2008). Ignatian Advocacy. Centro Prodh. Recuperado de: https://ignatianadvocacy.files.wordpress.com/2008/11/centroprodh_arriaga esp3.pdf

Comisión Nacional de Derechos Humanos. (2011). Informe especial sobre secuestro de migrantes en México. Recuperado el 5 de febrero de 2016, de CNDH: http://www.cndh.org.mx/sites/all/doc/Informes/Especiales/2011_secmigrantes.pdf

Descola, P. (2012). Más allá de la naturaleza y la cultura. Barcelona: Amorrortu.

Escobar, A. (15 de junio de 2015). La defensora de los migrantes, Doña Conchi, en el desamparo. Diálogo Queretano: Recuperado de: http://dialogoqueretano.com.mx/defensora-de-los-migrantes-centroamericanos-en-eldesamparo /

Escobar, A. (27 de abril de 2007). La samaritana del Ahorcado. Recuperado el 12 de febrero de 2016, de Diálogo Queretano. Recuperado de: http://dialogoqueretano.com.mx/la-samaritana-de-el-ahorcado/

Fassin, D. (2016). La razón humanitaria. Una historia moral del tiempo presente. Buenos Aires: Prometeo.

Flores, M. (18-20 de mayo de 2011). Experiencias positivas de la migración centroamericana en tránsito por México en las localidades de Veracruz, Tabasco y Estado de México. Recuperado el 15 de febrero de 2016, de Ponencia. Recuperado de: http://rimd.reduaz.mx/ponencias_flacso/PonenciaMarianaFlores.pdf

Fuentes, G. y Ortíz, L. (2012). El migrante centroamericano en su paso por México. Una revisión a su condición social desde la perspectiva de los derechos humanos. Convergencia, 19(58), 157-182.

Geertz, C. (2005). La interpretación de las culturas. Barcelona: Gedisa.

Godelier, M. (1998). El enigma del Don. Barcelona: Paidós.

González-Murphy, L., y Koslowski, R. (2011). Entendiendo el cambio de las leyes de inmigración en México. Recuperado el 12 de marzo de 2016, de Woodrow Wilson 
Internacional Center for Scholars. México Institute. Recuperado de: https://www.wilsoncenter.org/sites/default/files/KOSLOWSKI\%20SPANISH1.pdf

Instituto Tecnológico Autónomo de México. (2014). Migración centroamericana en tránsito por México hacia Estados Unidos. Diagnóstico y recomendaciones. Hacia una visión integral, regional y de responsabilidad compartida. México: ITAM. Recuperado de: http://migracionentransito.org/wpcontent/documents/Informe $\% 20 \mathrm{de} \% 20 \mathrm{Migraci} \% 23 \mathrm{U} 00 \mathrm{f} 3 \mathrm{n} \% 20 \mathrm{al} \% 2022 \% 20 \mathrm{julio} \% 2$ 02014\%20versi\%23U00f3n\%20electr\%23U00f3nica.pdf

Marcus, G. (1995). Ethnography in/of the Word System: The Emergence of Multi-Sited Ethnography. Annual Review of Anthropology (24), 95-117.

Mauss, M. (2012 [1925]). Ensayo sobre el don. Forma y función de intercambio en las sociedades arcaicas. Madrid: Katz Editores.

Morales, L. (2012). Categorías migratorias en México. Análisis de la Ley de Migración. Anuario Temático de Derecho Internacional, XII, 929-958.

Olayo, A. (2014). Refining the Concept of the Migration Industry: The Emergence of a Humanitarian Aid Network in the Mexican Corridor. Dissertation. University of Oxford.

Olayo, A., Haymes, S. y Vidal, M. (2014). Mexican Migration-Corridor Hospitality. Peace Review: A Journal of Social Justice, 26(2), 209-2017.

Servicio Jesuita a Migrantes. (2013). Narrativas de la transmigración centroamericana en su paso por México. Informe estadístico sobre las características de los transmigrantes centroamericanos. Servicio Jesuita a Migrantes. Recuperado de: https://dioscaminaconsupueblo.files.wordpress.com/2013/12/trilogc3ada1-estudioestadc3adstico.pdf

Solano, P. (2017). Assisting in the Shadows: Humanitarianism, Shelters and Transit Migrations Politics. Doctoral Dissertation. Lund University.

Squire, V. (2015). Post/Humanitarian Border Politics between Mexico and the US: People, Places, Things. Hampshire/New York: Palgrave Macmillan.

Suprema Corte de Justicia de la Federación. (2008). Tesis jurispridencial 33/2008. Semanario Judicial de la Federación. Recuperado de: https://www.scjn.gob.mx/Primera Sala/Tesis Jurisprudenciales/TesisJurisprudencial es20090619_2008.pdf

Testart, A. (2013). What's ir a gift. Journal of Ethnographic Theory, 3(1), 249-261.

Villafuente, D. y García, M. (2015). Crisis del sistema migratorio y seguridad en las fronteras norte y sur de México. REHMU. Revista Interdisciplinar de Movilidad Humana, 18(44), 83-98. 